\title{
The model homologue of the partially defective human 5,10-methylenetetrahydrofolate reductase, considered as a risk factor for stroke due to increased homocysteine level, can be protected and reactivated by heat shock proteins
}

\author{
Michal Grabowski $^{1}$ • Bogdan Banecki ${ }^{1}$ - Leszek Kadziński ${ }^{1}$ • \\ Joanna Jakóbkiewicz-Banecka ${ }^{2}$ - Magdalena Gabig-Cimińska ${ }^{3}$ - Alicja Węgrzyn ${ }^{3}$. \\ Grzegorz Wegrzyn $^{2} \cdot$ Zyta Banecka-Majkutewicz $^{4}$
}

Received: 13 January 2016 / Accepted: 20 May 2016 /Published online: 28 May 2016

(C) The Author(s) 2016. This article is published with open access at Springerlink.com

\begin{abstract}
The A222 V substitution in the human MTHFR gene product $(5,10$-methylenetetrahydrofolate reductase) is responsible for a decreased activity of this enzyme. This may cause an increased homocysteine level, considered as a risk factor for arteriosclerosis and stroke. The bacterial homologue of the human enzyme, MetF, has been found to be a useful model in genetic and biochemical studies. The similarity of Escherichia coli MetF and human MTHFR proteins is so high that particular mutations in the corresponding human gene can be reflected by the bacterial mutants. For example, the A222 V substitution in MTHFR (caused by the C667T substitution in the MTHFR gene) can be ascribed to the A117 V substitution in MetF. Here, it is reported that a temperature-sensitive MetF117 (A117 V) protein can be partially protected from a thermal inactivation by the heat shock proteins from the Hsp70/100 systems. Moreover, activity of the thermally denatured enzyme can be partially restored by the same heat shock proteins. High temperature protein $G$ (HtpG) had no effect on MetF117 activity in both experimental systems. The presented results indicate that functions of
\end{abstract}

Zyta Banecka-Majkutewicz

zytabm@gumed.edu.pl

1 Intercollegiate Faculty of Biotechnology, University of Gdańsk and Medical University of Gdańsk, Kładki 24, 80-822 Gdańsk, Poland

2 Department of Molecular Biology, University of Gdańsk, Wita Stwosza 59, 80-308 Gdańsk, Poland

3 Laboratory of Molecular Biology (affiliated with the University of Gdańsk), Institute of Biochemistry and Biophysics, Polish Academy of Sciences, Wita Stwosza 59, 80-308 Gdańsk, Poland

4 Department of Neurology, Medical University of Gdańsk, Dębinki 7, 80-211 Gdańsk, Poland heat shock proteins may be required for maintenance of the MetF117 function. This may have implications for the mechanisms of arteriosclerosis and stroke, especially in the light of previous findings that the A222 V MTHFR polymorphism may be a risk factor for stroke, as well as recently published results which demonstrated the increased levels of antibodies against heat shock proteins in stroke patients.

Keywords 5,10-methylenetetrahydrofolate reductase . Escherichia coli MetF protein · Human MTHFR gene . Homocysteine $\cdot$ Heat shock proteins

\section{Introduction}

5,10-Methylenetetrahydrofolate reductase (EC 1.5.1.20) is encoded in humans by the MTHFR gene. This enzyme is involved in homocysteine metabolism (presented schematically in Fig. 1), as it catalyses the conversion of 5,10-methylenetetrahydrofolate to 5-methyltetrahydrofolate, which serves as a methyl donor in the remethylation of homocysteine to methionine (Bailey and Gregory 1999). Therefore, dysfunction or decreased activity of the MTHFR gene product leads to increased levels of homocysteine. Hyperhomocysteinemia causes toxicity to vascular and nervous systems (Perła-Kaján et al. 2007). Thus, this metabolic defect is considered a risk factor for various diseases, including stroke, minimal cognitive impairment, dementia, Parkinson disease, multiple sclerosis, epilepsy, and eclampsia (for reviews see Ansari et al. 2014; Keshteli et al. 2015).

Among diseases for which hyperhomocysteinemia is a risk factor, stroke is one of the most severe disorders (for a review, see Banecka-Majkutewicz et al. 2012). Increased levels of 


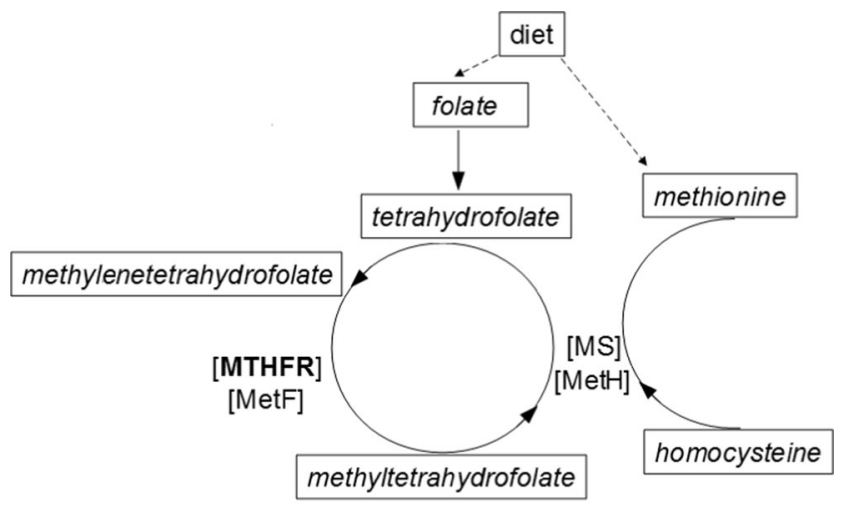

MTHFR - methylenetetrahydrofolate reductase MTHFR C677T - themosensitive variant of MTHFR MetF - bacterial homologue of MTHFR

MetF117 - bacterial homologue of MTHFR C677T

Fig. 1 Homocysteine metabolic pathway diagram detailing the human and bacterial methylenetetrahydrofolate reductase. MTHFR - human methylenetetrahydrofolate reductase, MetF - E.coli methylenetetrahydrofolate reductase, MS - methionine synthase, MetH - E.coli methionine synthase

homocysteine was correlated with the incidence of stroke in as various populations as those from Poland (Sawuła et al. 2009) and Karachi (Sadiq et al. 2014). Recent studies indicate that in stroke patients there are increased levels of antibodies against heat shock proteins (Hsps) (Banecka-Majkutewicz et al. 2014). Such results might suggest an essential role for Hsp deficiency in development of the atherosclerosis and stroke. However, the exact role of Hsps in putative stroke prevention remains unclear. Some light on this problem was shed by studies demonstrating that the Hsp70/100 system has a role in maintaining activity of Escherichia coli MetH protein, a homologue of human methionine synthase, another enzyme involved in homocysteine metabolism (Grabowski et al. 2012; Fig. 1). Since there is a high similarity between E. coli MetH and human methionine synthase, one might suggest that increased levels of anti-Hsps antibodies might reduce the efficiency of the chaperone systems, thus interfering with the homocysteine metabolism.

Continuing this line of studies, we aimed to investigate a potential role for Hsps in modulation of activity of the $E$. coli MetF protein, a homologue of the human 5,10-methylenetetrahydrofolate reductase (MTHFR). The level of similarity between these enzymes is so high that particular amino acid residues in MetF can be ascribed to their counterparts in MTHFR. For example A117 in MetF corresponds to A222 in MTHFR (Guenther et al. 1999). On the basis of structural and biochemical properties of the mutated form of MetF (A117 V), a specific mechanism leading to decreased activity and increased thermolability of the A222 V variant of MTHFR has been suggested (Guenther et al. 1999). The A222 V substitution is an effect of a common polymorphism in the MTHFR gene, the $\mathrm{C}$ to $\mathrm{T}$ transition at nucleotide position 677 (Ueland et al. 2001). It was demonstrated that human homozygotes with two $677 \mathrm{~T}$ alleles have a high concentration of plasma homocysteine, while heterozygotes may reveal moderate hyperhomocysteinemia, relative to $667 \mathrm{C}$ homozygotes (Kluijtmans and Whitehead 2001). Subsequent studies indicated that the $E$. coli system, in which production of wild-type or the A117 V variant of the MetF enzyme or both is allowed, can efficiently mimic human wild-type homozygote, A222 V homozygote or heterozygote, respectively, in activities of methylenetetrahydrofolate reductase (Jakobkiewicz-Banecka et al. 2005). This indicated that the E. coli MetF protein can be successfully employed as a model in studies on the human MTHFR enzyme, and has opened new possibilities of more detailed investigations, including aspects related to human diseases. In fact, there is no doubt that experiments with bacterial systems are significantly simpler and easier to work with than studies on human subjects, thus, the bacterial model of the human enzyme is particularly useful. It was demonstrated that among other phenotypes, bacteria expressing the metF 117 allele produces a thermosensitive $117 \mathrm{~V}$ variant of MetF which biochemically and physiologically corresponds to a thermolabile A222 V variant of human MTHFR (Jakobkiewicz-Banecka et al. 2005). Therefore, in this work, we aimed to use the MetF117 protein to test whether Hsps can contribute to the function of the thermolabile methylenetetrahydrofolate reductase.

\section{Materials and methods}

\section{Proteins}

Overproduction of proteins was performed in E. coli BL21(DE3) RIL in TB medium with 5 M FAD. The wildtype MetF protein was purified as described previously (Sheppard et al. 1999). The 117 variant of MetF was purified analogously as the wild-type enzyme, but all buffers used for purification of MetF117 were supplemented with $5 \mu \mathrm{M}$ FAD.

DnaK, GrpE, DnaJ, ClpB and HtpG were overproduced and purified according to the previously published methods (Banecki and Zylicz 1996; Banecki et al. 1996; Spence and Georgopoulos 1989; Woo et al. 1992; Wawrzynów et al. 1995).

\section{Determination of methylenetetrahydrofolate reductase activity}

Determination of methylenetetrahydrofolate reductase was performed as described previously (Sheppard et al. 1999), by measuring a decrease in absorbance of NADH, consumed during the reaction. The reaction mixture consisted of $50 \mathrm{mM}$ phosphate buffer containing $10 \%$ glycerol, $0.3 \mathrm{mM}$ EDTA, 
$400 \mu \mathrm{M}$ NADH, and $1.4 \mathrm{mM}$ menadione (vitamin $\mathrm{K} 3$ was used as an artificial substrate for MetF). The activity of MetF was determined by measurement of the kinetics of the reaction at $37^{\circ} \mathrm{C}$. The reaction mixture was prepared without the enzyme, and incubated for $5 \mathrm{~min}$. Following reaction initiation by the addition of $0.3 \mu \mathrm{M}$ enzyme, the measurement was carried out for $30 \mathrm{~min}$, by monitoring the absorbance at a wavelength of $340 \mathrm{~nm}$.

\section{Hsps protection of MetF117 from temperature-mediated denaturation}

MetF (at final concentration of $0.3 \mu \mathrm{M}$ ) was pre-incubated in the presence of $50 \mathrm{mM}$ phosphate buffer $(\mathrm{pH}$ 7.2) containing $10 \%$ glycerol, $0.3 \mathrm{mM}$ EDTA, $50 \mathrm{mM} \mathrm{NaCl}, 20 \mathrm{mM} \mathrm{KCl}$, $20 \mathrm{mM} \mathrm{MgCl}_{2}$, and in the presence of DnaK, DnaJ, GrpE, ClpB (the Hsp 70/100 system) or HtpG, and $5 \mathrm{mM}$ ATP. The concentrations of heat shock proteins were $3.7 \mu \mathrm{M}, 1.4 \mu \mathrm{M}$, $0.36 \mu \mathrm{M}, 1.5 \mu \mathrm{M}$, respectively for Hsp 70/100, and 3.6 $\mu \mathrm{M}$ for HtpG. The incubation was carried out for $15 \mathrm{~min}$ at $50{ }^{\circ} \mathrm{C}$. Finally, the samples were subjected to the MetF activity test.

\section{Reactivation of thermally-denatured MetF117 by Hsps}

MetF (at final concentration of $0.3 \mu \mathrm{M}$ ) was thermally inactivated by $15 \mathrm{~min}$ incubation at $50{ }^{\circ} \mathrm{C}$ in the presence of $50 \mathrm{mM}$ phosphate buffer $(\mathrm{pH}=7.2)$ containing $10 \%$ glycerol, $0.3 \mathrm{mM}$ EDTA, $50 \mathrm{mM} \mathrm{NaCl}, 20 \mathrm{mM} \mathrm{KCl}$, and $20 \mathrm{mM}$ $\mathrm{MgCl}_{2}$. Following the incubation, the enzyme was renatured in the presence of Hsp 70/100 or HtpG at the concentrations indicated in the preceding subsection. The renaturation was carried out for $45 \mathrm{~min}$ at $20{ }^{\circ} \mathrm{C}$. Finally, the samples were subjected to the MetF activity test.

\section{Statistical analysis}

Statistical analysis was performed using T-test. A $p$ value $<0.05$ was considered to indicate statistical significance. Each experiment was repeated three times. All data were calculated with Statistica 12 software (StatSoft).

\section{Results}

Wild-type and the $117 \mathrm{~V}$ variant of $E$. coli methylenetetrahydrofolate reductase, MetF and MetF117, respectively, were purified from bacteria overexpressing corresponding $m e t F$ alleles from a plasmid. We found that both variants of the enzyme had similar activities at $37^{\circ} \mathrm{C}$ (Fig. 2a).

To test effects of an increased temperature on MetF activity, the reaction mixtures were incubated at various temperatures. Significantly higher thermosensitivity of MetF117, relative to the wild-type enzyme, was observed (Fig. 2b). For further
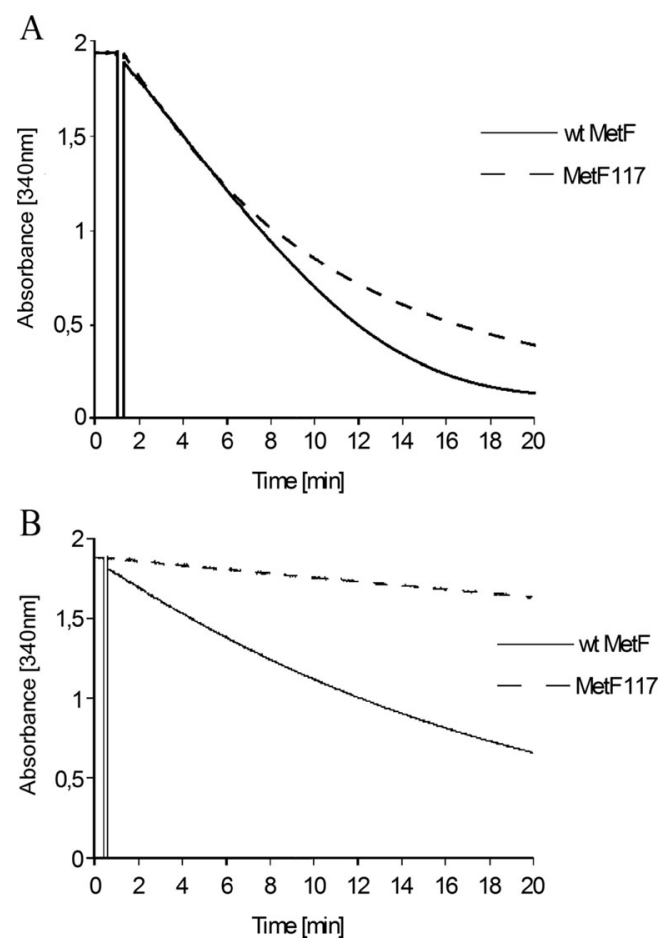

Fig. 2 The reaction kinetics of wild-type MetF and MetF117 at $37{ }^{\circ} \mathrm{C}$ (panel a) and at $50{ }^{\circ} \mathrm{C}$ (panel b). The enzymatic activity is reflected by a decrease in NADH absorbance, as this compound is consumed during the reaction

experiments, temperature $50{ }^{\circ} \mathrm{C}$ was chosen, at which the difference between both variants of the enzyme was the most pronounced.

We found that the proteins from the Hsp70/100 system, DnaK, DnaJ, GroEL, ClpB, could partially protect the MetF117 protein against thermal denaturation (Fig. 3a). The mutated enzyme revealed a significantly higher activity at $50{ }^{\circ} \mathrm{C}$ in the presence of the Hsp70/100 systems than in the absence of Hsps ( $p=0.0012$; t-test). HtpG had no significant effect on MetF117 activity ( $p=0.4667$; t-test).

When testing a reactivation of the previously thermallydenatured MetF117, we found that the Hsp70/100 system is able to partially recover the enzyme activity (Fig. 3b; $p=0.015$; t-test). Again, HtpG was unable to restore MetF117 activity ( $p=0.5$; t-test). Therefore, we conclude that Hsps can both partially protect and rescue MetF117 activity at elevated temperature.

\section{Discussion}

The results presented in this report indicate that Hsps have important roles in activation of the mutated MetF variant. The in vitro experiments were performed at $50{ }^{\circ} \mathrm{C}$ to demonstrate the most pronounced effects which occurred at an extremely high temperature relative to physiological conditions. However, most probably, similar functions of the Hsp70/100 

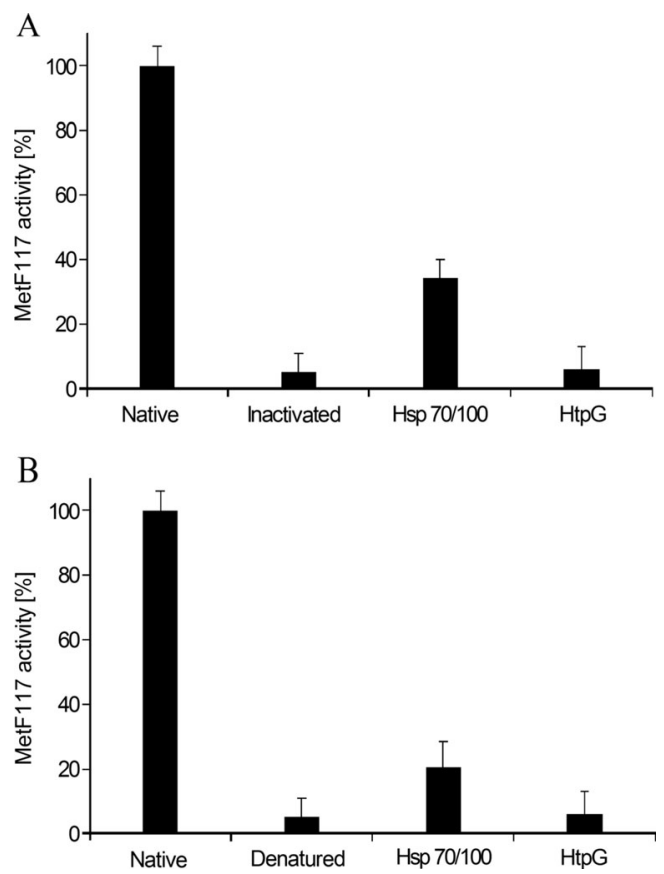

Fig. 3 The protection against heat-mediated inactivation (panel a) and reactivation of thermally-denatured (panel B) MetF117 enzyme by Hsp70/100 and HtpG hsps. Control experiments (Native) were performed at $37^{\circ} \mathrm{C}$. Heat-mediated inactivation reaction (panel a) was carried out for $15 \mathrm{~min}$ at $50^{\circ} \mathrm{C}$ in the absence (Inactivated) or presence of Hsp70/100 or HtpG. Denaturation of the enzyme (panel b) was performed by its incubation for $15 \mathrm{~min}$ at $50{ }^{\circ} \mathrm{C}$, and the reactivation reaction was carried out for $45 \mathrm{~min}$ at $20^{\circ} \mathrm{C}$ in the absence (Denatured) or presence of Hsp70/100 or HtpG

system may be important at physiological temperatures in living organisms. This assumption is based on the fact that at higher temperature the negative effects on the protein function should be more pronounced than at a lower one, thus, their correction is more difficult. Moreover, the Hsp70/100 system should work more efficiently under physiological conditions than at the extremely high temperature. Hence, if the system works under drastic conditions, it is likely that it also works in the living organism. Unfortunately, in the artificial in vitro system, the easily detected and unequivocally measurable effects occurred only at high temperature. On the other hand, this system provided a possibility to obtain a clear response to the asked question, due to its simplicity and the presence of only those factors which activities were investigated.

Because of the high similarity, both structural (Guenther et al. 1999) and functional (Jakobkiewicz-Banecka et al. 2005), between bacterial MetF and human MTHFR proteins, and their thermosensitive variants $117 \mathrm{~V}$ and $222 \mathrm{~V}$, respectively, we suggest that some implications can be proposed for the human organism. The $667 \mathrm{~T}$ allele of the MTHFR gene has been shown to cause a decreased activity of the encoded enzyme, and an increased levels of homocysteine, even if occurring in the heterozygotic state (Kluijtmans and Whitehead 2001). Moreover, hyperhomocysteinemia was considered a risk factor for stroke (Sawuła et al. 2009; Ansari et al. 2014; Sadiq et al. 2014). Nevertheless, it is obvious that not all persons having an increased plasma level of homocysteine suffer from stroke. Therefore, other factors, agents and/or conditions must also be involved in the mechanism of an increased risk of this disorder in persons with hyperhomocysteinemia. One of them may be Hsps, as these proteins can modulate activity of methylenetetrahydrofolate reductase, and particularly its thermolabille form.

It is tempting to speculate that if the Hsp70/100 system is fully functional, the activity of the thermolabille MTHFR is sufficient to keep the homocysteine level low enough to avoid an increased risk for stroke. However, it was reported that in stroke patients, as well as patients in whom stroke occurred in the past, there are increased levels of anti-Hsps antibodies (Banecka-Majkutewicz et al. 2014). These antibodies could inactivate Hsps, resulting in less efficient protection or reactivation of the mutant MTHFR, and in turn, increased levels of homocysteine, leading to a high risk for stroke. Along to this hypothesis, it is worth reminding that the Hsp70/100 system can also maintain appropriate activity of methionine synthase (Grabowski et al. 2012), and dysfunction of this enzyme can also cause hyperhomocysteinemia (Matthews and Elmore 2007). Intriguingly, HtpG had no effect on protection or renaturation of MetF117, thus, these reactions appear to be specific to the Hsp70/100 system. At the current stage of our knowledge, the reason and mechanism of such specificity are unclear and require further extensive studies, which extend beyond the aims of this study. We are aware that such a proposal requires experimental and clinical verifications in studies on the human biological material, nevertheless, this report indicates a possibility by which different factors might interplay in the way of stroke occurrence.

Acknowledgments This work was supported by National Science Center (Poland) project grant no. 2011/02/A/NZ1/00009 to G.W.

\section{Compliance with ethical standards}

Competing interests The authors declare that they have no competing interests.

Open Access This article is distributed under the terms of the Creative Commons Attribution 4.0 International License (http:// creativecommons.org/licenses/by/4.0/), which permits unrestricted use, distribution, and reproduction in any medium, provided you give appropriate credit to the original author(s) and the source, provide a link to the Creative Commons license, and indicate if changes were made.

\section{References}

Ansari R, Mahta A, Mallack E, Luo JJ (2014) Hyperhomocysteinemia and neurologic disorders: a review. J Clin Neurol 10:281-288 
Bailey LB, Gregory JF III (1999) Polymorphism of methylenetetrahydrofolate reductase and other enzymes: metabolic significance, risk and impact on folate requirement. J Nutr 129:919-922

Banecka-Majkutewicz Z, Sawuła W, Kadziński L, Papkov A, Węgrzyn A, Banecki B (2012) Homocysteine, heat shock proteins, genistein and vitamins in ischemic stroke - pathogenic and therapeutic implications. Acta Biochim Pol 59:495-499

Banecka-Majkutewicz Z, Grabowski M, Kadziński L, Węgrzyn A, Banecki B (2014) Increased levels of antibodies against heat shock proteins in stroke patients. Acta Biochim Pol 61:379-383

Banecki B, Zylicz M (1996) Real time kinetics of the DnaK/DnaJ/GrpE molecular chaperone machine action. J Biol Chem 271:6137-6143

Banecki B, Liberek K, Wall D, Wawrzynów A, Georgopoulos C, Bertoli E, Tanfani F, Zylicz M (1996) Structure-function analysis of the zinc finger region of the DnaJ molecular chaperone. J Biol Chem 271: 14840-14848

Grabowski M, Banasiuk R, Węgrzyn A, Kędzierska B, Lica J, BaneckaMajkutewicz Z, Banecki B (2012) Role of heat-shock proteins and cobalamine in maintaining methionine synthase activity. Acta Biochim Pol 59:489-493

Guenther BD, Sheppard CA, Tran P, Rozen R, Matthews RG, Ludwig ML (1999) The structure and properties of methylenetetrahydrofolate reductase from Escherichia coli suggest how folate ameliorates human hyperhomocysteinemia. Nat Struct Biol 6:359-365

Jakobkiewicz-Banecka J, Kloska A, Stepnowska M, Banecki B, Wegrzyn A, Wegrzyn G (2005) A bacterial model for studying effects of human mutations in vivo: Escherichia coli strains mimicking a common polymorphism in the human MTHFR gene. Mutat Res 578:175-186

Keshteli AH, Baracos VE, Madsen KL (2015) Hyperhomocysteinemia as a potential contributor of colorectal cancer development in inflammatory bowel diseases: a review. World J Gastroenterol 21:1081-1090
Kluijtmans LAJ, Whitehead AS (2001) Methylenetetrahydrofolate reductase genotypes and predisposition to atherothrombotic disease. Evidence that all three MTHFR C677T genotypes confer different levels of risk. Eur Heart J 22:294-299

Matthews RG, Elmore CL (2007) Defects in homocysteine metabolism: diversity among hyperhomocyst (e)inemias. Clin Chem Lab Med 45:1700-1703

Perła-Kaján J, Twardowski T, Jakubowski H (2007) Mechanisms of homocysteine toxicity in humans. Amino Acids 32:561-572

Sadiq M, Alam MT, Kanpurwala MA, Khan MS (2014) Frequency of hyper homocysteinaemia in ischaemic stroke patients of Karachi. J Pak Med Assoc 64:1063-1066

Sawuła W, Banecka-Majkutewicz Z, Kadziński L, JakóbkiewiczBanecka J, Wegrzyn G, Nyka W, Banecki B (2009) Homocysteine level and metabolism in ischemic stroke in the population of northern Poland. Clin Biochem 42:442-447

Sheppard CA, Trimmer EE, Matthews RG (1999) Purification and properties of NADH-dependent 5, 10-methylenetetrahydrofolate reductase (MetF) from Escherichia coli. J Bacteriol 181:718-725

Spence J, Georgopoulos C (1989) Purification and properties of the Escherichia coli heat shock protein, HtpG. J Biol Chem 264: 4398-4403

Ueland PM, Hustad S, Schneede J, Refsum H, Vollset SE (2001) Biological and clinical implications of the MTHFR C677T polymorphism. Trends Pharmacol Sci 22:195-201

Wawrzynów A, Banecki B, Wall D, Liberek K, Georgopoulos C, Zylicz M (1995) ATP hydrolysis is required for the DnaJ-dependent activation of DnaK chaperone for binding to both native and denatured protein substrates. J Biol Chem 270:19307-19311

Woo KM, Kim KI, Goldberg AL, Ha DB, Chung CH (1992) The heatshock protein $\mathrm{ClpB}$ in Escherichia coli is a protein-activated ATPase. J Biol Chem 267:20429-20434 